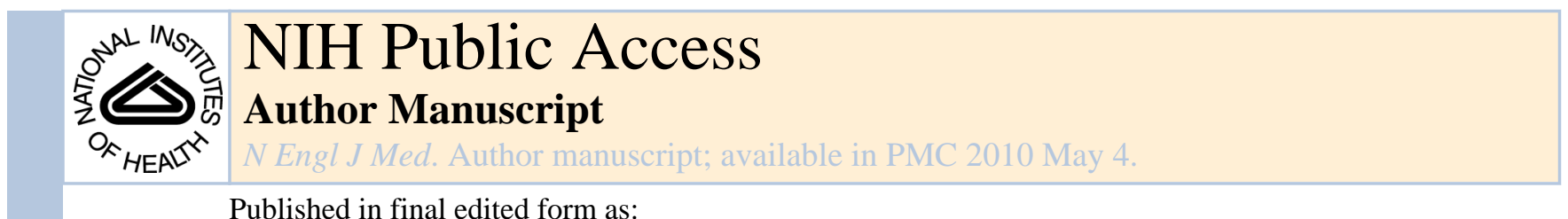

NEngl J Med. 2009 June 11; 360(24): 2503-2515. doi:10.1056/NEJMoa0805796.

\title{
A Randomized Trial of Therapies for Type 2 Diabetes and Coronary Artery Disease
}

\author{
The BARI 2D Study Group*
}

Abstract

Background-Optimal treatment for patients with both type 2 diabetes mellitus and stable ischemic heart disease has not been established.

Methods-We randomly assigned 2368 patients with both type 2 diabetes and heart disease to undergo either prompt revascularization with intensive medical therapy or intensive medical therapy alone and to undergo either insulin-sensitization or insulin-provision therapy. Primary end points were the rate of death and a composite of death, myocardial infarction, or stroke (major cardiovascular events). Randomization was stratified according to the choice of percutaneous coronary intervention $(\mathrm{PCI})$ or coronary-artery bypass grafting $(\mathrm{CABG})$ as the more appropriate intervention.

Results-At 5 years, rates of survival did not differ significantly between the revascularization group $(88.3 \%)$ and the medical-therapy group $(87.8 \%, \mathrm{P}=0.97)$ or between the insulinsensitization group (88.2\%) and the insulin-provision group (87.9\%, $\mathrm{P}=0.89)$. The rates of freedom from major cardiovascular events also did not differ significantly among the groups: $77.2 \%$ in the revascularization group and $75.9 \%$ in the medical-treatment group $(\mathrm{P}=0.70)$ and $77.7 \%$ in the insulin-sensitization group and $75.4 \%$ in the insulin-provision group $(\mathrm{P}=0.13)$. In the PCI stratum, there was no significant difference in primary end points between the revascularization group and the medical-therapy group. In the CABG stratum, the rate of major cardiovascular events was significantly lower in the revascularization group (22.4\%) than in the medical-therapy group ( $30.5 \%, \mathrm{P}=0.01 ; \mathrm{P}=0.002$ for interaction between stratum and study group). Adverse events and serious adverse events were generally similar among the groups, although

Address for correspondence: Maria Mori Brooks, PhD, Department of Epidemiology, University of Pittsburgh, GSPH, 130 DeSoto Street / A530 Crabtree Hall, Pittsburgh, PA 15261, Telephone: (412) 624-1618, FAX: (412) 383-8690, mbrooks@ pitt.edu.

A complete listing of The BARI 2D Study Group is provided in Appendix C.

Writing team: Robert L. Frye, M.D., Mayo Clinic, Rochester, MN; Phyllis August, M.D., M.P.H., New York Hospital Queens, Queens, NY; Maria Mori Brooks, Ph.D., Regina M. Hardison, M.S., Sheryl F. Kelsey, Ph.D., Joan M. MacGregor, M.S., and Trevor J. Orchard, M.B., B.Ch., University of Pittsburgh, Pittsburgh; Bernard R. Chaitman, M.D., Saint Louis University, St. Louis; Saul M. Genuth, M.D., Case Western Reserve University, Cleveland; Suzanne H. Goldberg, R.N., M.S.N., National Heart, Lung, and Blood Institute, Bethesda, MD; Mark A. Hlatky, M.D., Stanford University, Palo Alto, CA; Teresa L.Z. Jones, M.D., National Institute of Diabetes and Digestive and Kidney Diseases, Bethesda, MD; Mark E. Molitch, M.D., Feinberg School of Medicine, Northwestern University, Chicago; Richard W. Nesto, M.D., Lahey Clinic Medical Center, Burlington, MA; Edward Y. Sako, M.D., Ph.D., University of Texas Health Science Center, San Antonio; and Burton E. Sobel, M.D., University of Vermont, Burlington

We dedicate this article to the memory of Katherine M. Detre, M.D., Dr.P.H., who initiated and led this study with a commitment to enhance the care of patients through the rigorous analysis of clinical evidence

Dr. Frye reports serving on advisory boards for Sanofi-Aventis and Schering-Plough; Dr. Kelsey, serving on advisory boards for Sanofi-Aventis and Axio; Dr. Orchard, receiving consulting fees from AstraZeneca, Eli Lilly, and Takeda and grant support from VeraLight and having an equity interest in Bristol-Myers Squibb; Dr. Chaitman, receiving consulting fees from Eli Lilly and lecture fees from CV Therapeutics; Dr. Genuth, receiving consulting fees from Takeda, Sanofi-Aventis, and Merck; Dr. Hlatky, receiving consulting fees from Blue Cross Blue Shield Technology Evaluation Center and GE Healthcare and grant support from Aviir; Dr. Jones, having an equity interest in Amgen; Dr. Molitch, receiving consulting and lecture fees from Sanofi-Aventis and grant support from Amgen, Eli Lilly, Tercica, and Corcept Therapeutics; and Dr. Nesto, receiving consulting and lecture fees from GlaxoSmithKline and Sanofi-Aventis. No other potential conflict of interest relevant to this article was reported. 
severe hypoglycemia was more frequent in the insulin-provision group $(9.2 \%)$ than in the insulinsensitization group $(5.9 \%, \mathrm{P}=0.003)$.

Conclusions-Overall, there was no significant difference in the rates of death and major cardiovascular events between patients undergoing prompt revascularization and those undergoing medical therapy or between strategies of insulin sensitization and insulin provision.

(ClinicalTrials.gov number, NCT00006305.)

\section{Keywords}

Type 2 Diabetes Mellitus; Coronary Artery Disease; Clinical Trials; Coordinated Care;

Revascularization; Insulin Sensitization

Patients with type 2 diabetes mellitus have a higher risk of cardiovascular events and death than those without diabetes. ${ }^{1,2,3,4}$ Few large, randomized trials have addressed the question of the optimal treatment for patients with diabetes and angiographically defined stable ischemic heart disease. The Bypass Angioplasty Revascularization Investigation 2 Diabetes (BARI 2D) trial was designed to test treatment strategies for patients with coronary artery disease and diabetes. Our goal was to address the effects of therapy on the rate of myocardial ischemia, a major cause of death in patients with diabetes, and of insulin resistance, the fundamental mechanism underlying diabetes with profound cardiovascular consequences. 5,6

Among patients with diabetes, studies have indicated that increased insulin levels predict adverse outcomes ${ }^{7,8}$ and that control of hyperglycemia by reducing insulin resistance, rather than by providing insulin, might improve cardiovascular outcomes. This approach is tempered by data suggesting a limited benefit ${ }^{9}$ or possible harm ${ }^{10,11}$ associated with the use of newer insulin-sensitizing thiazolidinedione drugs and the failure of three recent trials to show reductions in cardiovascular events from intensifying glucose control beyond the current recommendations of the American Diabetes Association. ${ }^{12}$

Although the effectiveness of coronary revascularization in relieving angina is well established, its benefit in reducing the rates of subsequent myocardial infarction and death has been shown only in patients with high-risk profiles ${ }^{13,14}$ or acute coronary syndromes. ${ }^{15,16}$ Studies of coronary revascularization in patients with moderate ${ }^{17}$ or with mild or no symptoms have had conflicting results. ${ }^{18,19}$ However, such trials have not focused on patients with diabetes, who are at high risk with even mild symptoms of myocardial ischemia.

Thus, we evaluated two cardiac treatment strategies and two glycemic treatment strategies in patients who were receiving uniform glycemic control and intensive therapy for cardiac risk factors. ${ }^{20}$ Our first hypothesis was that prompt revascularization (either surgical or catheterbased) would reduce long-term rates of death and cardiovascular events, as compared with medical therapy alone. Our second hypothesis was that a strategy of insulin sensitization (with a target level for glycated hemoglobin of less than 7.0\%) would reduce long-term rates of death and cardiovascular events, as compared with a strategy of insulin provision.

\section{Methods}

\section{Study Population}

From January 1, 2001, to March 31, 2005, patients were enrolled at 49 clinical sites in the United States, Canada, Brazil, Mexico, the Czech Republic, and Austria. Treatment continued until the 6-year visit or until the last annual visit before December 1, 2008. Patients who were still enrolled in the trial were contacted between September and 
November 2008; national database searches were conducted for patients with unknown vital status.

Eligibility criteria included a diagnosis of both type 2 diabetes and coronary artery disease. The diagnosis of type 2 diabetes was based on the need for treatment with insulin or oral hypoglycemic drugs or a confirmed elevated blood glucose level. The diagnosis of coronary artery disease was documented on angiography ( $\geq 50 \%$ stenosis of a major epicardial coronary artery associated with a positive stress test or $\geq 70 \%$ stenosis of a major epicardial coronary artery and classic angina). All patients had to be candidates for elective percutaneous coronary intervention (PCI) or coronary-artery bypass grafting (CABG). Patients were excluded if they required immediate revascularization or had left main coronary disease, a creatinine level of more than $2.0 \mathrm{mg}$ per deciliter ( $177 \mu \mathrm{mol}$ per liter), a glycated hemoglobin level of more than $13.0 \%$, class III or IV heart failure, or hepatic dysfunction or if they had undergone PCI or CABG within the previous 12 months.

\section{Treatment Strategies}

Patients were randomly assigned to two treatment strategies in a 2-by-2 factorial design. In the first strategy, patients were assigned to undergo either prompt coronary revascularization or medical therapy. In the second strategy, patients were assigned to undergo either insulinsensitization therapy or insulin-provision therapy to achieve a target glycated hemoglobin level of less than $7.0 \%$. A key feature of the trial was that randomization was stratified according to the method of revascularization (PCI or CABG), as determined a priori by the responsible physician to be the more appropriate therapy for each patient (Figure 1).

Patients in the revascularization group were to undergo the procedure within 4 weeks after randomization, whereas patients in the medical-therapy group were to undergo revascularization during follow-up only if such therapy were clinically indicated by the progression of angina or the development of an acute coronary syndrome or severe ischemia. ${ }^{21}$ Patients in the insulin-sensitization group could receive insulin-providing drugs, and patients in the insulin-provision group could receive insulin-sensitizing drugs if the glycated hemoglobin level could not otherwise be maintained below $8.0 \%$.

All patients were treated according to current guidelines, with a target level for glycated hemoglobin of less than 7.0\%, a low-density lipoprotein (LDL) cholesterol level of less than $100 \mathrm{mg}$ per deciliter (2.6 mmol per liter), and a blood pressure of 130/80 $\mathrm{mm} \mathrm{Hg}$ or less. In addition, all patients received counseling regarding smoking cessation, weight loss, and regular exercise. Clinical management centers monitored and provided feedback on riskfactor control. ${ }^{22}$ Patients were seen monthly for the first 6 months and every 3 months thereafter.

\section{Evaluation of Outcomes}

The primary end point was death from any cause, and the principal secondary end point was a composite of death, myocardial infarction, or stroke (major cardiovascular events). The definition of nonfatal myocardial infarction included spontaneous, silent, and procedurerelated events. According to the study's protocol, 12-lead electrocardiography was performed at baseline, at 3 months, at 1 year, and annually thereafter, before and after each revascularization procedure, and at the time of suspected ischemic events. The diagnosis of spontaneous myocardial infarction was based on a doubling of cardiac biomarkers (creatine kinase MB or troponin) and evidence of ischemia on the basis of symptoms, electrocardiography, or imaging. Major cardiovascular events that were associated with PCI and $\mathrm{CABG}$ required an increase in the upper limit of the normal range for creatine kinase MB of 3 times and 10 times, respectively. Silent myocardial infarction was defined as a Q- 
wave change of two grades on routine electrocardiography, according to the Minnesota code (see the Supplementary Appendix.) Myocardial infarction was classified by the Core Electrocardiography Laboratory; stroke and cause of death were adjudicated by an independent clinical events committee. Core laboratory staff and committee members were unaware of study-group assignments.

\section{Study Design}

The trial design and baseline characteristics of the patients have been described previously. $21,22,23,24,25$ The protocol was approved by the institutional review board at the University of Pittsburgh and at each participating site. All patients provided written informed consent. Investigators at 49 clinical sites collected data, which were analyzed at the University of Pittsburgh. An independent data and safety monitoring board approved the study protocol and monitored the safety of patients. The trial was sponsored by the National Institutes of Health, with additional support from industry. Industry sponsors did not have access to outcome data at any time during the trial and did not participate in data analyses or the preparation of the manuscript.

\section{Statistical Analysis}

We compared baseline characteristics, follow-up measures, and clinical outcomes on an intention-to-treat basis according to the randomized study-group assignment. Continuous variables were compared with Student's t-test or Wilcoxon nonparametric statistics and categorical variables with chi-square statistics. Cross-sectional follow-up data were presented at 3 years, since follow-up ranged from 3 to 6 years. We compared rates of death and major cardiovascular events using Kaplan-Meier survival curves and log-rank statistics with a two-sided alpha level of 0.05 . Within strata defined by the intended method of revascularization, we compared end points in the revascularization group and the medicaltherapy group using a log-rank test at a two-sided alpha level of $0.01 .{ }^{24}$ Cox proportionalhazards regression models that included study-group assignment, stratum, and assigned study group according to stratum interaction were used to determine whether the studygroup effect was significantly modified by the intended method of revascularization. In addition, the statistical interactions between the cardiac study groups and the glycemic study groups for rates of death and major cardiovascular events were tested overall and within the PCI and CABG strata at a two-sided alpha level of 0.05. Follow-up data regarding the rate of death were censored at the time of the last contact with the patient, whereas data for the principal secondary end point were censored at the last study-clinic visit.

In 2005 , the follow-up period was extended by 1.5 years to increase the average follow-up to 5.3 years because recruitment of patients took longer than planned and the original target of 2800 patients was not met. The extension was designed to provide a power of $88 \%$ to detect a $30 \%$ reduction in the rate of death (from $14.0 \%$ to $9.8 \%$ ) and a power of $95 \%$ to detect a $25 \%$ reduction in the rate of major cardiovascular events (from $24.0 \%$ to $18.0 \%$ ).

\section{Results \\ Patients}

All the patients underwent clinically indicated coronary angiography before randomization; most of them provided consent during screening before angiography but after meeting clinical eligibility requirements. Thus, the number of patients who were excluded for reasons unrelated to coronary anatomy is unavailable. Of the 4623 patients with type 2 diabetes who consented to screening, 2187 were ineligible for randomization; 68 eligible patients declined to participate, and the remaining 2368 patients underwent randomization. ${ }^{24}$ 
Baseline characteristics were well balanced among the study groups (Table 1 in the Supplementary Appendix). Myocardial ischemia was symptomatic in $82.1 \%$ of patients, and the mean duration of diabetes was 10.4 years. The average follow-up was 5.3 years, and 2194 patients $(92.7 \%)$ completed the study as designed (Figure 1 in the Supplementary Appendix).

\section{Study Treatments}

Coronary revascularization was performed within 6 months in $95.4 \%$ of patients in the revascularization group, as compared with $13.0 \%$ of patients in the medical-therapy group (Figure 2 in the Supplementary Appendix). At 5 years, $42.1 \%$ of patients in the medicaltherapy group ( $43.3 \%$ in the PCI stratum and $39.7 \%$ in the CABG stratum) had undergone clinically indicated revascularization. Nearly $90 \%$ of patients in both the insulinsensitization group and the insulin-provision group were taking their assigned medications at 3 years, although $43.4 \%$ of patients in the insulin-sensitization group and $11.8 \%$ of those in the insulin-provision group received medications from the alternative drug class to obtain adequate glycemic control (Figure 2 in the Supplementary Appendix).

Among 765 patients in the revascularization group who underwent PCI, procedures were attempted on a mean $( \pm \mathrm{SD})$ of $1.5 \pm 0.8$ lesions. Of these procedures, $20.7 \%$ involved a multivessel intervention; $34.7 \%$ of the patients received a drug-eluting stent, and $56.0 \%$ received a bare-metal stent; the other $9.3 \%$ did not receive a stent. After drug-eluting stents became available in April 2003, 61.0\% of the initial PCI procedures involved the use of such stents. Of the 347 patients in the revascularization group who underwent CABG, 36.0\% were treated off-pump, and $94.2 \%$ received an internal mammary-artery graft; a mean of $3.0 \pm 1.0$ distal anastomoses were performed. The 30 -day rate of death was $0.5 \%$ in the PCI subgroup and $1.4 \%$ in the CABG subgroup; the 30-day composite end point of death, myocardial infarction, or stroke occurred in $3.5 \%$ of the patients after PCI and in $4.6 \%$ after CABG.

At the 3-year follow-up, the most frequently used drugs in the insulin-provision group were insulin (60.7\%) and sulfonylurea (52.0\%); in the insulin-sensitization group, the most frequently used drugs were metformin (74.6\%) and a thiazolidinedione (62.1\%) (Table 1). At 3 years, $5.6 \%$ of the patients were being treated for diabetes with diet alone. Throughout follow-up, the mean glycated hemoglobin levels were significantly lower in the insulinsensitization group than in the insulin-provision group $(\mathrm{P}<0.001)$ (Table 1$)$.

All patients received intensive medical therapy during the trial in accordance with clinical guidelines, with common use of statins, aspirin, beta-blockers, and either angiotensinconverting-enzyme inhibitors or angiotensin-receptor blockers (Table 1). At 3 years, most patients had met treatment goals for levels of LDL cholesterol (82.6\%) and blood pressure $(71.1 \%)$. The body-mass index was significantly lower and levels of high-densitylipoprotein (HDL) cholesterol were significantly higher in the insulin-sensitization group than in the insulin-provision group during follow-up (Table 1).

\section{Primary and Principal Secondary Outcomes}

The rates of death from any cause did not differ significantly overall between the revascularization group and the medical-therapy group or between the insulin-sensitization group and the insulin-provision group (Figure 2). The 5-year rate of survival was $88.3 \%$ among patients in the revascularization group, as compared with $87.8 \%$ among patients in the medical-therapy group (difference, $0.5 \%$; 95\% confidence interval [CI], -2.0 to 3.1 ; $\mathrm{P}=0.97$ by the log-rank test). At 5 years, the rate of survival was $88.2 \%$ among patients in the insulin-sensitization group, as compared with $87.9 \%$ among patients in the insulin- 
provision group (difference, $0.3 \%$; $95 \% \mathrm{CI},-2.2$ to $2.9 ; \mathrm{P}=0.89$ by the log-rank test). The rate of freedom from major cardiovascular events did not differ significantly between the revascularization group and the medical-therapy group (difference, $1.3 \% ; 95 \% \mathrm{CI},-2.2$ to 4.9; $\mathrm{P}=0.70$ ) or between the insulin-sensitization group and the insulin-provision group (difference, $2.4 \% ; 95 \% \mathrm{CI},-1.2$ to $6.0 ; \mathrm{P}=0.13$ ) (Figure 2).

\section{Revascularization Strata}

The patients for whom CABG was prespecified as the intended method of revascularization had more extensive coronary disease, ${ }^{26}$ with significantly more three-vessel disease, proximal disease of the left anterior descending artery, and chronic coronary occlusions than the patients for whom PCI was intended. Patients who were selected to undergo CABG were also more likely to have a history of myocardial infarction and less likely to have undergone previous coronary revascularization (Table 1 in the Supplementary Appendix).

The rate of death did not differ significantly between the revascularization group and the medical-therapy group in either the CABG or the PCI stratum (Figure 3). Patients in the CABG stratum who were assigned to the revascularization group had significantly fewer major cardiovascular events than did patients in the $\mathrm{CABG}$ stratum who were assigned to the medical-therapy group ( $\mathrm{P}=0.01)$ (Figure 3$)$. In contrast, rates of cardiovascular events among patients in the PCI stratum who were assigned to the revascularization group did not differ significantly from those who were assigned to the medical-therapy group (Figure 3). The interaction between study-group assignment and intended method of revascularization was statistically significant $(\mathrm{P}=0.002)$, which indicated that the benefit associated with prompt coronary revascularization, as compared with medical therapy, was significantly greater for patients selected for CABG than for patients selected for PCI. In the CABG stratum, nonfatal myocardial infarction occurred in markedly fewer patients in the revascularization group (7.4\%) than in the medical-therapy group (14.6\%) (Table 2 in the Supplementary Appendix).

\section{Evaluation of Treatment Combinations}

An analysis of the rates of death and major cardiovascular events among the four mutually exclusive groups - revascularization plus insulin sensitization, revascularization plus insulin provision, medical therapy plus insulin sensitization, and medical therapy plus insulin provision - revealed no significant heterogeneity ( $\mathrm{P}>0.05$ for interaction) or treatment differences $(\mathrm{P}>0.05$ for all four group comparisons by the log-rank test). When the analysis was stratified according to the intended method of revascularization, the rate of major cardiovascular events differed significantly among the four study groups in the CABG stratum $(\mathrm{P}=0.02)$, with the lowest rate seen in the group that underwent revascularization plus insulin sensitization; the interaction between the two treatments was of borderline significance $(\mathrm{P}=0.07)$ (Table 2). The effect of revascularization on the rate of cardiovascular events was particularly evident among patients in the CABG stratum who were assigned to the insulin-sensitizing strategy, with a rate of $18.7 \%$ among patients in the revascularization group, as compared with $32.0 \%$ among those in the medical-therapy group $(\mathrm{P}=0.002)$.

\section{Adverse Events}

Adverse event rates were infrequent and did not generally differ among the study groups (Table 3). However, severe hypoglycemia (which was defined as hypoglycemia requiring assistance with treatment and either a blood glucose level of $<50 \mathrm{mg}$ per deciliter [2.8 mmol per liter] or confusion, irrational or uncontrollable behavior, convulsions, or coma reversed by treatment that raises blood glucose levels) was more frequent among patients assigned to receive insulin provision $(9.2 \%)$ than among those who received insulin sensitization (5.9\%, $\mathrm{P}=0.003$ ). Among patients with no history of heart failure, the rate of new congestive heart 
failure did not differ significantly between patients in the insulin-sensitization group $(19.4 \%)$ and those in the insulin-provision group $(16.6 \%, \mathrm{P}=0.09)$. Peripheral pitting edema was more frequent in the insulin-sensitization group than in the insulin-provision group $(\mathrm{P}=0.02)$.

\section{Discussion}

Among patients with type 2 diabetes and stable ischemic heart disease receiving intensive medical therapy, there was little difference between insulin sensitization and insulin provision with respect to rates of death and cardiovascular events at 5 years. Likewise, a strategy of prompt coronary revascularization with the procedure most appropriate for the individual patient and a strategy of medical therapy led to similar clinical outcomes. Prompt revascularization significantly reduced major cardiovascular events, as compared with intensive medical therapy, among patients who were selected to undergo CABG but not among those who were selected to undergo PCI.

Our study was designed to compare coronary revascularization with intensive medical therapy, not to compare CABG with PCI. Patients who were selected to undergo CABG were expected to have higher event rates; indeed, among patients who were assigned to the medical-therapy group in the CABG stratum, the 5-year mortality (16.4\%) was much higher than that among patients assigned to medical therapy in the PCI stratum (10.2\%).

The study was designed to reflect how physicians might confront treatment decisions in practice. Our findings suggest that patients who have diabetes, evidence of myocardial ischemia, and extensive multivessel disease would benefit from prompt surgical revascularization mainly because of a lower rate of nonfatal myocardial infarction. However, for the many patients with type 2 diabetes who have less extensive coronary disease and for whom PCI is judged to be more appropriate, prompt revascularization did not reduce the risk of cardiovascular events, as compared with medical therapy. Approximately one third of patients in the PCI stratum who were assigned to undergo revascularization received a drug-eluting stent, but since these devices have not been shown to reduce rates of death or major cardiovascular events, ${ }^{27}$ their use probably did not affect the results.

It is important to note that all the patients who were assigned to receive medical therapy underwent careful clinical monitoring, and $42.1 \%$ had changes in the clinical course that called for later revascularization during 5 years of follow-up. In clinical practice, the initial treatment strategy for a patient with diabetes and coronary disease rarely remains constant over a 5-year period. The fact that most patients in the medical-therapy group did not require coronary revascularization during the 5-year period suggests that many patients may be safely treated with intensive medical therapy.

Our two-by-two factorial design allowed further comparisons between combinations of strategies. Among patients for whom CABG was selected as the intended method of revascularization, the combination of prompt revascularization and an insulin-sensitization strategy was associated with a significantly lower rate of major cardiovascular events than any of the other three treatment combination groups. Although previous studies have shown a beneficial effect on cardiovascular outcomes associated with the use of insulin sensitization with thiazolidinediones ${ }^{9,28,29}$ and metformin, ${ }^{30}$ our results cannot distinguish between the effect of either agent or the combination.

The strategies for glycemic control that we tested were not implemented at the time of initial diagnosis of diabetes, and there was inevitably less than complete differentiation of treatment regimens. The treatment regimens in our study reflect what is clinically possible 
for patients with established type 2 diabetes. Intensification of medical therapy and consistent monitoring led to improved control of cardiac risk factors across the board. Although only $28.4 \%$ of patients simultaneously achieved all three protocol targets at 3 years, the rates of control attained in this trial were much better than the rates recorded for community care 31,32 and similar to those reported in other trials. ${ }^{33,34}$

The mean follow-up glycated hemoglobin values in the insulin-sensitization group and the insulin-provision group were close to the target level of $7.0 \%$ but differed significantly from each other. The mean difference of less than $0.5 \%$ in glycated hemoglobin levels between the two glycemic-control strategies in our study was less than the mean difference of $1.6 \%$ in the Veterans Affairs Diabetes Trial (VADT) (ClinicalTrials.gov number, NCT00032487), 33 the difference of $1.1 \%$ in the Action to Control Cardiovascular Risk in Diabetes (ACCORD) trial (NCT00000620), ${ }^{35}$ and the difference of $0.6 \%$ in the Action in Diabetes and Vascular Disease: Preterax and Diamicron Modified Release Controlled Evaluation (ADVANCE) trial (NCT00145925). ${ }^{34}$ Since none of these trials that compared different glycemic-control targets showed a significant reduction in cardiovascular events, it is unlikely that our results were due solely to differences in the level of glycemic control.

In our study, plasma insulin levels were consistently lower over time in patients in the insulin-sensitization group (median, $6.3 \mu \mathrm{U}$ per milliliter) than in those in the insulinprovision group (median, $10.0 \mu \mathrm{U}$ per milliliter), a finding that is consistent with the mechanisms of action of metformin and thiazolidinediones. Despite the need to administer insulin or sulfonylureas to some patients, patients in the insulin-sensitization group were maintained at or very near the target level for glycated hemoglobin. Moreover, the insulinsensitization strategy was associated with fewer severe hypoglycemic episodes, less weight gain, and higher HDL levels than those in the insulin-provision strategy. These data may suggest that insulin sensitization is preferable for patients with type 2 diabetes and coronary disease.

Like all randomized clinical trials, our study was limited in terms of the generalizability of results to all patients with type 2 diabetes and coronary disease. Furthermore, confidence intervals for the overall between-group differences were within $3 \%$ for the rate of death and $6 \%$ for the rate of major cardiovascular events; smaller treatment effects could have been missed.

In summary, a strategy of prompt coronary revascularization in patients who had been treated with intensive medical therapy for diabetes and stable ischemic disease did not significantly reduce the rate of death from any cause or of major cardiovascular events. Insulin sensitization and insulin provision also had similar cardiovascular outcomes during a 5 -year period. Among patients for whom CABG was deemed to be the appropriate treatment, prompt revascularization reduced the rate of major cardiovascular events, as compared with medical therapy, particularly among patients who were assigned to receive insulin sensitization. In the PCI stratum, however, revascularization did not reduce the rate of death or major cardiovascular events when added to medical therapy.

\section{Supplementary Material}

Refer to Web version on PubMed Central for supplementary material.

\section{Acknowledgments}

Bypass Angioplasty Revascularization Investigation 2 Diabetes (BARI 2D) is funded by the National Heart, Lung and Blood Institute and the National Institute of Diabetes and Digestive and Kidney Diseases (U01 HL061744, U01 HL061746, U01 HL061748, U01 HL063804). BARI 2D received significant supplemental funding provided by 
GlaxoSmithKline, Collegeville, PA, Lantheus Medical Imaging, Inc. (formerly Bristol-Myers Squibb Medical Imaging, Inc.), North Billerica, MA, Astellas Pharma US, Inc., Deerfield, IL, Merck \& Co., Inc., Whitehouse Station, NJ, Abbott Laboratories, Inc., Abbott Park, IL, and Pfizer, Inc, New York, NY. Generous support is given by Abbott Laboratories Ltd., MediSense Products, Mississauga, Canada, Bayer Diagnostics, Tarrytown, NY, Becton, Dickinson and Company, Franklin Lakes, NJ, J. R. Carlson Labs, Arlington Hts., IL, Centocor, Inc., Malvern, PA, Eli Lilly and Company, Indianapolis, IN, LipoScience, Inc., Raleigh, NC, Merck Sante, Lyon, France, Novartis Pharmaceuticals Corporation, East Hanover, NJ, and Novo Nordisk, Inc. Princeton, NJ.

\section{References}

1. The Bypass Angioplasty Revascularization Investigation (BARI) Investigators. Comparison of coronary bypass surgery with angioplasty in patients with multivessel disease. N Engl J Med 1996;335:217-225. Erratum, N Engl J Med 1997;336:147. [PubMed: 8657237]

2. Geiss, LS.; Herman, WH.; Smith, PJ. Mortality in non-insulin-dependent diabetes. In: Aubert, RE.; Ballard, DJ.; Barrett-Connor, E., et al., editors. Diabetes in America (NIH publication no. 95-1468). 2nd. Bethesda, MD: National Institute of Diabetes and Digestive and Kidney Diseases; 1995. p. 233-57.

3. Mak KH, Moliterno DJ, Granger CB, et al. Influence of diabetes mellitus on clinical outcome in the thrombolytic era of acute myocardial infarction. J Am Coll Cardiol 1997;30:171-179. [PubMed: 9207639]

4. Malmberg K, Yusuf S, Gerstein HC, et al. Impact of diabetes on long-term prognosis in patients with unstable angina and non-Q-wave myocardial infarction: results of the OASIS (Organization to Assess Strategies for Ischemic Syndromes) Registry. Circulation 2000;102:1014-1019. [PubMed: 10961966]

5. Du X, Edelstein D, Obici S, Higham N, Zou MH, Brownlee M. Insulin resistance reduces arterial prostacyclin synthase and eNOS activities by increasing endothelial fatty acid oxidation. J Clin Invest 2006;116:1071-1080. [PubMed: 16528409]

6. Reaven GM. Banting Lecture 1988: role of insulin resistance in human disease. Diabetes 1988;37:1595-1607. [PubMed: 3056758]

7. Abizaid A, Kornowski R, Mintz GS, et al. The influence of diabetes mellitus on acute and late clinical outcomes following coronary stent implantation. J Am Coll Cardiol 1998;32:584-589. [PubMed: 9741497]

8. Kronmal RA, Barzilay JI, Tracy RP, Savage PJ, Orchard TJ, Burke GL. The relationship of fasting serum radioimmune insulin levels to incident coronary heart disease in an insulin-treated diabetic cohort. J Clin Endocrinol Metab 2004;89:2852-2858. [PubMed: 15181068]

9. Erdmann E, Dormandy JA, Charbonnel B, Massi-Benedetti M, Moules IK, Skene AM. The effect of pioglitazone on recurrent myocardial infarction in 2,445 patients with type 2 diabetes and previous myocardial infarction: results from the PROactive (PROactive 05) Study. J Am Coll Cardiol 2007;49:1772-1780. [PubMed: 17466227]

10. Nissen SE, Wolski K. Effect of rosiglitazone on the risk of myocardial infarction and death from cardiovascular causes. N Engl J Med 2007;356:2457-2471. Erratum, N Engl J Med 2007;357:100. [PubMed: 17517853]

11. Singh S, Loke YK, Furberg CD. Long-term risk of cardiovascular events with rosiglitazone: a meta-analysis. JAMA 2007;298:1189-1195. [PubMed: 17848653]

12. Skyler JS, Bergenstal R, Bonow RO, et al. Intensive glycemic control and the prevention of cardiovascular events: implications of the ACCORD, ADVANCE, and VA diabetes trials: a position statement of the American Diabetes Association and a scientific statement of the American College of Cardiology Foundation and the American Heart Association. Circulation 2009;119:351-357. [PubMed: 19095622]

13. Detre K, Murphy ML, Hultgren H. Effect of coronary bypass surgery on longevity in high and low risk patients: report from the V.A. Cooperative Coronary Surgery Study. Lancet 1977;2:12431245. [PubMed: 73949]

14. Yusuf S, Zucker D, Peduzzi P, et al. Effect of coronary artery bypass graft surgery on survival: overview of 10-year results from randomised trials by the Coronary Artery Bypass Graft Surgery Trialists Collaboration. Lancet 1994;344:563-570. Erratum, Lancet 1994;344:1446. [PubMed: 7914958] 
15. Lagerqvist B, Husted S, Kontny F, Ståhle E, Swahn E, Wallentin L. 5-Year outcomes in the FRISC-II randomised trial of an invasive versus a non-invasive strategy in non-ST-elevation acute coronary syndrome: a follow-up study. Lancet 2006;368:998-1004. [PubMed: 16980115]

16. Lakkis N, Tsyboulev V, Gibson CM, et al. Outcome of patients with acute coronary syndrome admitted to hospitals with or without onsite cardiac catheterization laboratory: a TACTICS-TIMI 18 substudy. Crit Pathw Cardiol 2002;1:232-237. [PubMed: 18340309]

17. Boden WE, O'Rourke RA, Teo KK, et al. Optimal medical therapy with or without PCI for stable coronary disease. N Engl J Med 2007;356:1503-1516. [PubMed: 17387127]

18. Pepine CJ, Bourassa MG, Chaitman BR, et al. Factors influencing clinical outcomes after revascularization in the Asymptomatic Cardiac Ischemia Pilot (ACIP). J Card Surg 1999;14:1-8. [PubMed: 10678439]

19. Coronary angioplasty versus medical therapy for angina: the second Randomised Intervention Treatment of Angina (RITA-2) trial. Lancet 1997;350:461-468. [PubMed: 9274581]

20. Gæde P, Lund-Andersen H, Parving HH, Pedersen O. Effect of a multifactorial intervention on mortality in type 2 diabetes. N Engl J Med 2008;358:580-591. [PubMed: 18256393]

21. Barsness GW, Gersh BJ, Brooks MM, Frye RL. Rationale for the revascularization arm of the Bypass Angioplasty Revascularization Investigation 2 Diabetes (BARI 2D) Trial. Am J Cardiol 2006;97 12A:31G-40G.

22. Albu J, Gottlieb SH, August P, Nesto RW, Orchard TJ. Modifications of coronary risk factors. Am J Cardiol 2006;97 12A:41G-52G.

23. Magee MF, Isley WL. Rationale, design, and methods for glycemic control in the Bypass Angioplasty Revascularization Investigation 2 Diabetes (BARI 2D) Trial. Am J Cardiol 2006;97 12A:20G-30G.

24. Brooks MM, Frye RL, Genuth S, et al. Hypotheses, design, and methods for the Bypass Angioplasty Revascularization Investigation 2 Diabetes (BARI 2D) Trial. Am J Cardiol 2006;97 12A:9G-19G.

25. Bypass Angioplasty Revascularization Investigation 2 Diabetes Study Group. Baseline characteristics of patients with diabetes and coronary artery disease enrolled in the Bypass Angioplasty Revascularization Investigation 2 Diabetes (BARI 2D) trial. Am Heart J 2008;156:528-536. [PubMed: 18760137]

26. Kim LS, King SB, Kent K. Factors related to the selection of surgical versus percutaneous revascularization in diabetic patients with multivessel coronary artery disease in the BARI 2D trial. J Am Coll Cardiol Intv 2009;2:384-92.

27. Trikalinos TA, Alsheikh-Ali AA, Tatsioni A, Nallamothu BK, Kent DM. Percutaneous coronary interventions for non-acute coronary artery disease: a quantitative 20-year synopsis and a network meta-analysis. Lancet 2009;373:911-918. [PubMed: 19286090]

28. Mazzone T, Meyer PM, Feinstein SB, et al. Effect of pioglitazone compared with glimepiride on carotid intima-media thickness in type 2 diabetes: a randomized trial. JAMA 2006;296:25722581. [PubMed: 17101640]

29. Nissen SE, Nicholls SJ, Wolski K, et al. Comparison of pioglitazone vs glimepiride on progression of coronary atherosclerosis in patients with type 2 diabetes: the PERISCOPE randomized controlled trial. JAMA 2008;299:1561-1573. [PubMed: 18378631]

30. UK Prospective Diabetes Study (UKPDS) Group. Effect of intensive blood-glucose control with metformin on complications in overweight patients with type 2 diabetes (UKPDS 34). Lancet 1998;352:854-865. Erratum, Lancet 1998;352:1558. [PubMed: 9742977]

31. George PB, Tobin KJ, Corpus RA, Devlin WH, O'Neill WW. Treatment of cardiac risk factors in diabetic patients how well do we follow the guidelines? Am Heart J 2001;142:857-863. [PubMed: 11685175]

32. McFarlane SI, Jacober SJ, Winer N, et al. Control of cardiovascular risk factors in patients with diabetes and hypertension at urban academic medical centers. Diabetes Care 2002;25:718-723. [PubMed: 11919131]

33. Duckworth W, Abraira C, Moritz T, et al. Glucose control and vascular complications in veterans with type 2 diabetes. N Engl J Med 2009;360:129-139. [PubMed: 19092145] 
34. The ADVANCE Collaborative Group. Intensive blood glucose control and vascular outcomes in patients with type 2 diabetes. N Engl J Med 2008;358:2560-2572. [PubMed: 18539916]

35. The Action to Control Cardiovascular Risk in Diabetes Study Group. Effects of intensive glucose lowering in type 2 diabetes. N Engl J Med 2008;358:2545-2559. [PubMed: 18539917] 
Enrollment Flow Diagram

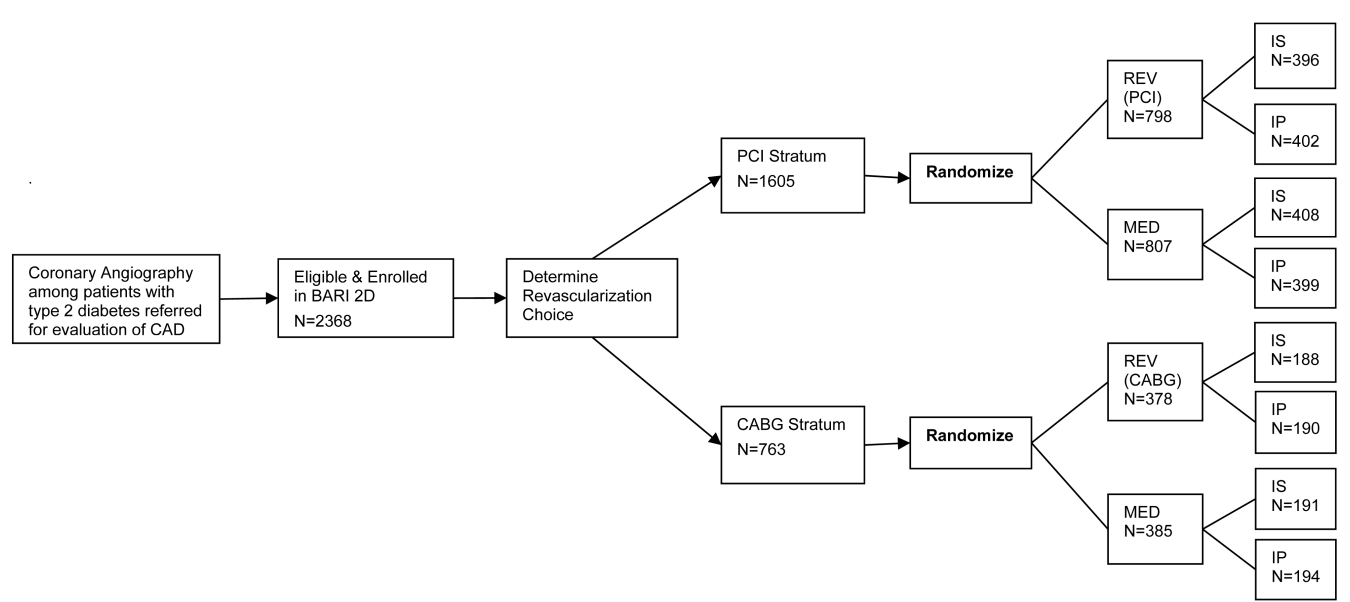

Figure 1.

The flow chart depicting the BARI 2D the sequence of selecting the intended revascularization randomization stratum followed by the assignment of the randomized treatment groups. 

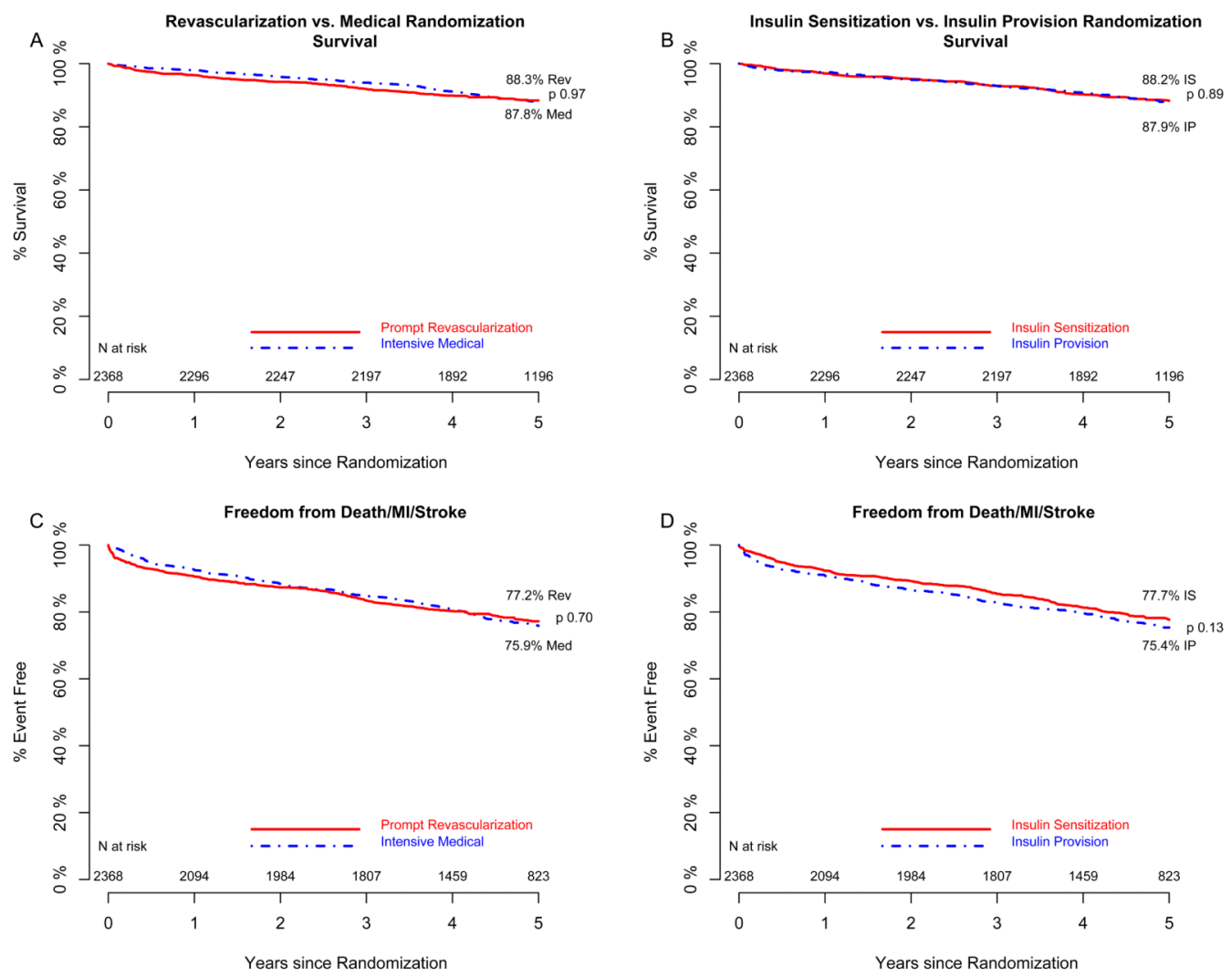

Figure 2.

The estimated percent of patients surviving in the prompt revascularization (Panel A solid line) and intensive medical (Panel A dashed line) and in the insulin sensitization (Panel B solid line) and insulin provision (Panel B dashed line) randomized treatment groups. The estimated percent of patients free of major cardiovascular events in the prompt revascularization (Panel $\mathrm{C}$ solid line) and intensive medical (Panel $\mathrm{C}$ dashed line) and in the insulin sensitization (Panel D solid line) and insulin provision (Panel D dashed line) randomized treatment groups. 

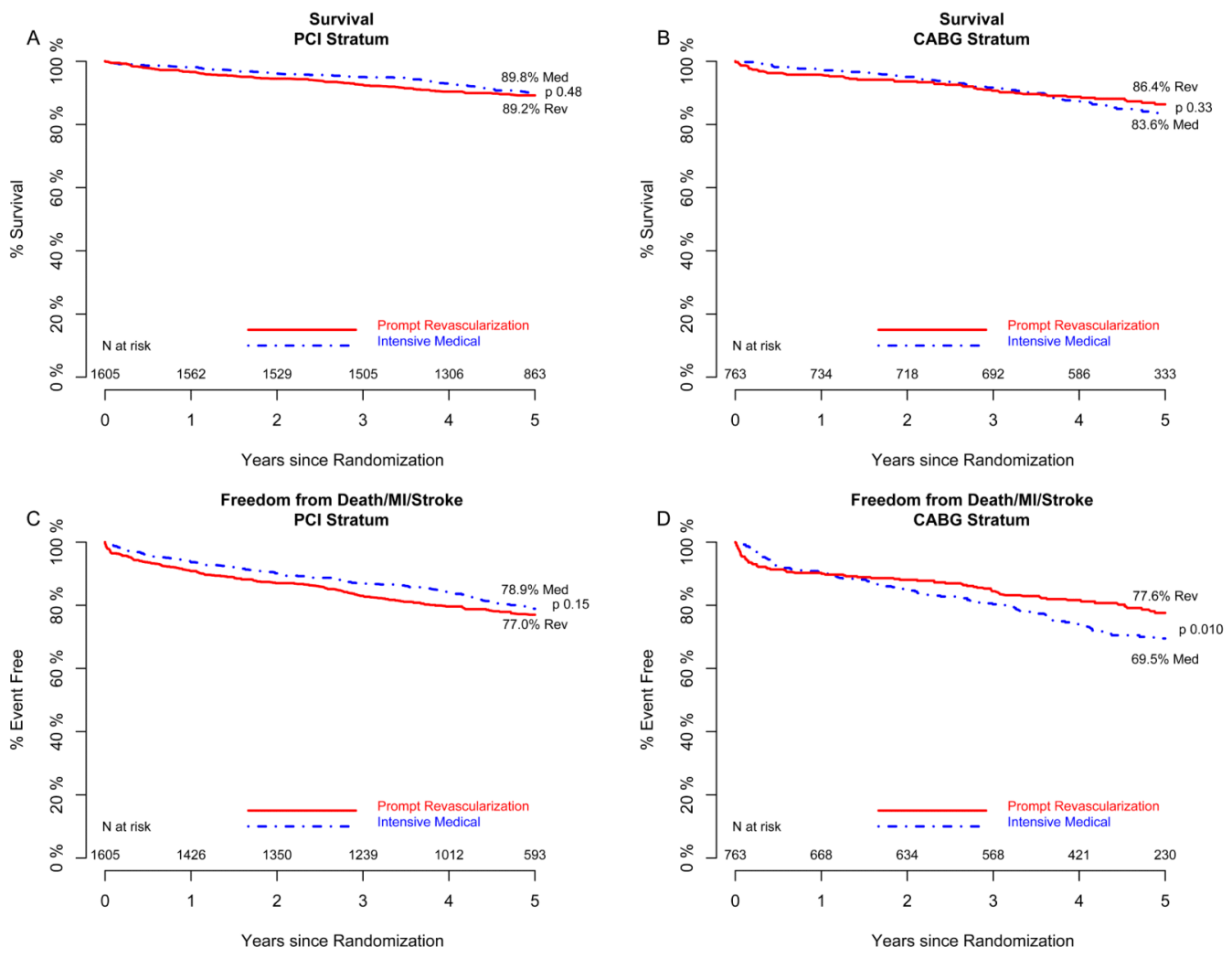

Figure 3.

The estimated percent of patients surviving in the prompt revascularization (solid line) and intensive medical (dashed line) randomized treatment groups within the intended PCI stratum (Panel A) and within the intended CABG stratum (Panel B). The estimated percent of patients free of major cardiovascular events in the prompt revascularization (solid line) and the intensive medical (dashed line) randomized treatment groups within the intended PCI stratum (Panel C) and within the intended CABG stratum (Panel D). 


\begin{tabular}{|c|c|c|c|c|c|c|c|c|c|c|c|c|c|c|c|c|c|c|c|c|c|c|c|c|c|c|}
\hline & $=$ & & $\mid \begin{array}{l}\overrightarrow{0} \\
\dot{\vec{v}} \\
\vec{v}\end{array}$ & $\mid \begin{array}{l}\overrightarrow{\dot{\theta}} \\
\dot{\vec{v}}\end{array}$ & 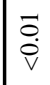 & $\begin{array}{l}\overrightarrow{0} \\
\dot{\theta} \\
\dot{\theta}\end{array}$ & 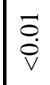 & $\begin{array}{l}\bar{\sigma} \\
\stackrel{0}{0}\end{array}$ & 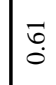 & f. & ¿ & $\begin{array}{c}\infty \\
\stackrel{\infty}{\infty} \\
\stackrel{0}{0}\end{array}$ & in & & $\begin{array}{l}\bar{\delta} \\
\dot{\sigma} \\
\dot{v}\end{array}$ & $\mid \begin{array}{l}\bar{\delta} \\
\dot{\sigma} \\
\dot{v}\end{array}$ & $\begin{array}{l}\hat{A} \\
0\end{array}$ & Fे & $\begin{array}{l}\vec{\delta} \\
\dot{0} \\
\dot{v}\end{array}$ & त̄ & 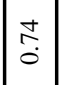 & $\overrightarrow{\tilde{o}}$ & $\stackrel{t}{m}$ & in & $\begin{array}{l}\tilde{\delta} \\
0 \\
0\end{array}$ & $\stackrel{0}{0}$ \\
\hline & 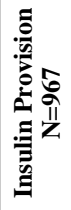 & & $\stackrel{\ddots}{\varrho}$ & $\stackrel{\vec{r}}{\vec{r}}$ & $\vec{i}$ & 穴 & $\hat{8}$ & $\begin{array}{l}3 \\
\infty \\
\infty\end{array}$ & $\frac{\partial}{\sigma}$ & 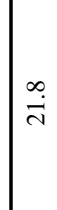 & হे & $\stackrel{\stackrel{\vec{\lambda}}{\vec{\lambda}}}{ }$ & f & & 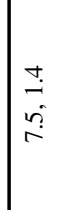 & $\mid \begin{array}{l}n \\
0 \\
0 \\
0 \\
0\end{array}$ & $\begin{array}{l}n \\
\tilde{n} \\
\tilde{n} \\
n\end{array}$ & $\begin{array}{l}\hat{N} \\
\dot{\infty}\end{array}$ & $\begin{array}{l}= \\
\dot{q}\end{array}$ & $\begin{array}{l}\vec{\infty} \\
\vec{m} \\
\vec{m}\end{array}$ & 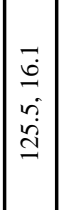 & $\mid \begin{array}{l}m \\
0 \\
0 \\
\stackrel{0}{R} \\
尺\end{array}$ & 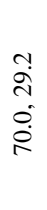 & 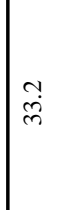 & $\begin{array}{l}\tilde{y} \\
\text { ñ } \\
i \\
\tilde{n}\end{array}$ & 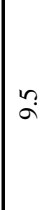 \\
\hline 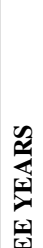 & 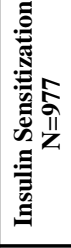 & & $\begin{array}{l}0 \\
\dot{+} \\
i\end{array}$ & $\overrightarrow{\mathrm{j}}$ & $\vec{n}$ & $\begin{array}{l}\mathscr{D} \\
\stackrel{\infty}{\Omega}\end{array}$ & $\begin{array}{l}n \\
\text { nd } \\
\text { ind }\end{array}$ & $\begin{array}{l}n \\
\infty \\
\infty\end{array}$ & $\stackrel{m}{a}$ & 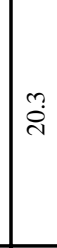 & $\stackrel{\infty}{\alpha}$ & $\stackrel{\mathrm{C}}{ }$ & zू & & $\mid$ & \begin{tabular}{|c|c}
$\vec{r}$ \\
$\hat{\tilde{s}}$ \\
$\tilde{3}$
\end{tabular} & $\begin{array}{l}\vec{m} \\
\vec{n} \\
\underline{m}\end{array}$ & $\begin{array}{l}\hat{\lambda} \\
\hat{i}\end{array}$ & $\begin{array}{l}\mathcal{I} \\
\mathcal{g}\end{array}$ & 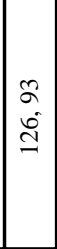 & 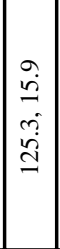 & $\mid \begin{array}{l}\infty \\
0 \\
0 \\
\dot{0} \\
\dot{0} \\
\end{array}$ & 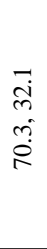 & $\underset{\dot{m}}{\stackrel{+}{+}}$ & $\begin{array}{l}3 \\
\tilde{b} \\
\dot{m} \\
\dot{m}\end{array}$ & $\overrightarrow{\mathrm{I}}$ \\
\hline $\bar{F}$ & $=$ & & 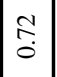 & $\mid \begin{array}{l}\infty \\
\infty \\
\infty \\
0\end{array}$ & 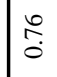 & $\stackrel{8}{\stackrel{8}{*}}$ & $\stackrel{9}{0}$ & $\bar{\circ}$ & ñ & $\begin{array}{l}\overline{0} \\
\dot{\vec{v}}\end{array}$ & gे & $\begin{array}{l}\text { " } \\
\stackrel{\circ}{\circ} \\
\stackrel{0}{0}\end{array}$ & 吕 & & તุ. & $\frac{0}{5}$ & $:$ & đa & ถి & లె & $\mid \begin{array}{l}\infty \\
n \\
o \\
0\end{array}$ & $\hat{\imath}$ & త్ర & $\hat{\imath}$ & in & : \\
\hline & 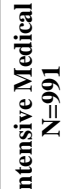 & & $\mid \begin{array}{l}\hat{y} \\
\dot{y}\end{array}$ & $\begin{array}{l}\tilde{m} \\
\tilde{m}\end{array}$ & तें & ले & 尔 & $\stackrel{\partial}{\infty}$ & ঙু & ఝై & fु & $\stackrel{\odot}{\vec{N}}$ & $\begin{array}{l}m \\
n \\
n\end{array}$ & & 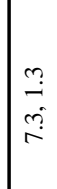 & 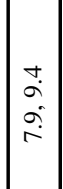 & 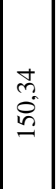 & $\mid \begin{array}{l}1 \\
2 \\
2 \\
2\end{array}$ & $\begin{array}{l}\simeq \\
\dot{F}\end{array}$ & $\mid \begin{array}{l}\infty \\
\infty \\
-\dot{m}\end{array}$ & 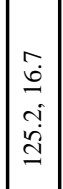 & $\left|\begin{array}{c}n \\
0 \\
0 \\
\tilde{r} \\
2 \\
2\end{array}\right|$ & $\begin{array}{l}\overrightarrow{0} \\
\dot{\tilde{m}} \\
0 \\
\stackrel{8}{8}\end{array}$ & $\bar{f}$ & 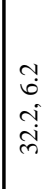 & $\stackrel{\overbrace{}}{=}$ \\
\hline & 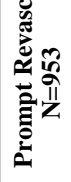 & & $\overrightarrow{\dot{q}}$ & \begin{tabular}{|l}
$\infty$ \\
i \\
in
\end{tabular} & $\begin{array}{l}\infty \\
\dot{d} \\
\dot{d}\end{array}$ & लें & $\begin{array}{l}\text { 文 } \\
\stackrel{j}{y}\end{array}$ & હે & $\frac{\pi}{\sigma}$ & ñ & & $\stackrel{\mathrm{C}}{ }$ & $\dot{0}$ & & $\underset{\substack{i\\
}}{\stackrel{n}{2}}$ & $\mid$\begin{tabular}{c}
\multirow{0}{0}{} \\
$\stackrel{0}{\infty}$ \\
$\stackrel{\infty}{\sim}$
\end{tabular} & $\mid \begin{array}{l}m \\
\stackrel{n}{n} \\
\end{array}$ & $\mid \begin{array}{c}\infty \\
\stackrel{1}{0} \\
\dot{\infty}\end{array}$ & $\begin{array}{l}= \\
\dot{F}\end{array}$ & $\mid \begin{array}{l}8 \\
0 \\
0 \\
0\end{array}$ & $\mid \begin{array}{c}1 \\
0 \\
0 \\
0 \\
0 \\
\vdots \\
0\end{array}$ & $\left|\begin{array}{l}\stackrel{0}{0} \\
\dot{8} \\
\stackrel{2}{\gtrless}\end{array}\right|$ & $\begin{array}{l}\hat{\partial} \\
\dot{m} \\
\hat{m} \\
\stackrel{2}{R}\end{array}$ & $\begin{array}{l}n \\
m \\
m\end{array}$ & $\begin{array}{l}3 \\
0 \\
0 \\
0 \\
i \\
0\end{array}$ & $\stackrel{+}{\stackrel{\circ}{\varrho}}$ \\
\hline$\frac{\sqrt{z}}{3}$ & ¿ & & $\mid \begin{array}{l}\dot{p} \\
\dot{i n}\end{array}$ & $\stackrel{\infty}{\infty}$ & $\stackrel{\text { ڤn }}{\varrho}$ & हैं & $\overrightarrow{\grave{\lambda}}$ & ते & $\vec{E}$ & $\frac{m}{m}$ & $\begin{array}{l}0 . \\
\infty \\
\infty\end{array}$ & $\stackrel{\stackrel{\rho}{0}}{\stackrel{\infty}{2}}$ & 竎 & & 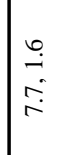 & $\mid \begin{array}{l}m \\
= \\
\dot{2}\end{array}$ & $\begin{array}{l}7 \\
\dot{8} \\
\dot{0}\end{array}$ & \begin{tabular}{|l}
$\hat{3}$ \\
$\overbrace{}^{2}$
\end{tabular} & $\left|\begin{array}{l}0 \\
\infty \\
\infty \\
\infty\end{array}\right|$ & 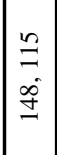 & 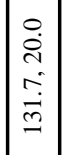 & 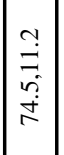 & 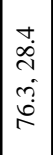 & i & $\begin{array}{l}0 \\
\dot{0} \\
\dot{\sim} \\
\dot{m}\end{array}$ & $\stackrel{\infty}{\vec{\Lambda}}$ \\
\hline & & $\therefore$ & 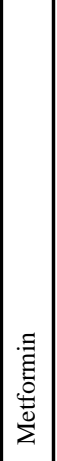 & 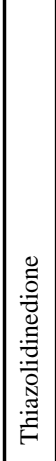 & 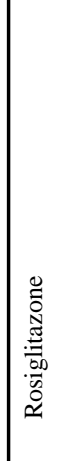 & 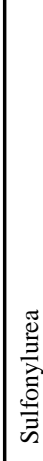 & 言 & 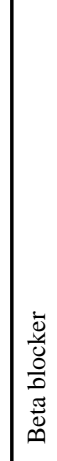 & 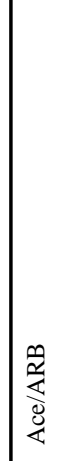 & 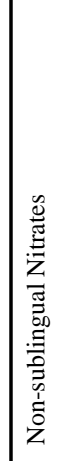 & 影 & 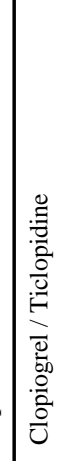 & 㞼 & 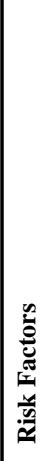 & 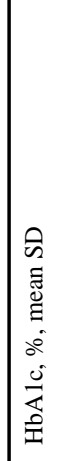 & 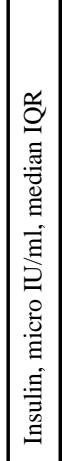 & 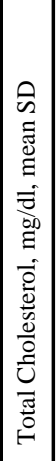 & 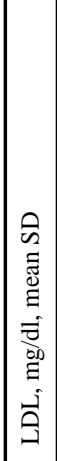 & 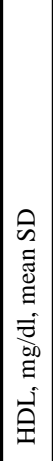 & 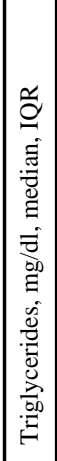 & 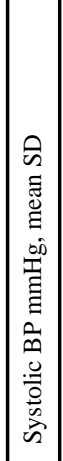 & 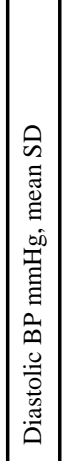 & 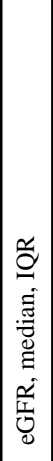 & 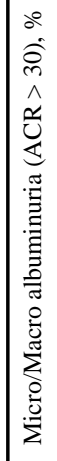 & 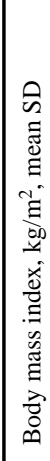 & 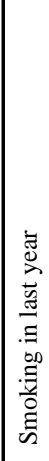 \\
\hline
\end{tabular}




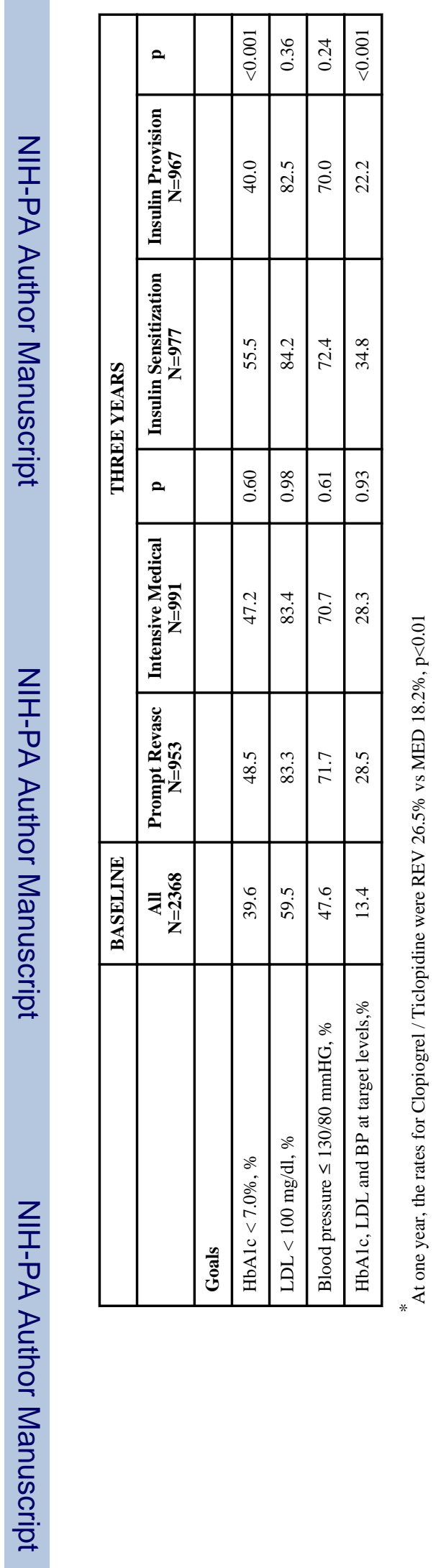

N Engl J Med. Author manuscript; available in PMC 2010 May 4. 


\begin{tabular}{|c|c|c|c|c|c|c|c|c|c|c|c|c|}
\hline & 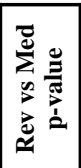 & તે & : & 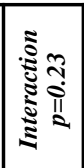 & 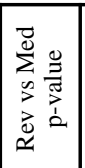 & గొ & 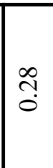 & 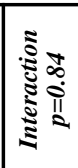 & 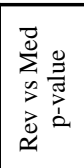 & 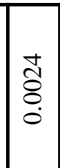 & 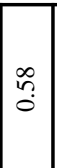 & 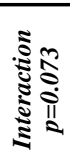 \\
\hline 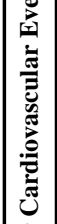 & 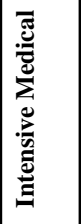 & $\begin{array}{l}\stackrel{\circ}{-} \\
\stackrel{+}{d}\end{array}$ & $\frac{\stackrel{2}{+}}{\dot{d}}$ & $\begin{array}{l}\swarrow 0 \\
\infty \\
0\end{array}$ & 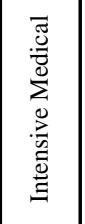 & 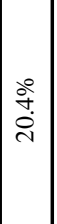 & $\frac{\stackrel{\circ}{2}}{\stackrel{i}{N}}$ & $\bar{n}$ & 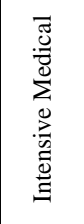 & $\begin{array}{c}\stackrel{0}{0} \\
\text { i } \\
\tilde{c}\end{array}$ & \begin{tabular}{|l|}
$\vdots$ \\
$\vdots$ \\
$\dot{i}$
\end{tabular} & $\bar{n}$ \\
\hline & 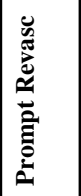 & 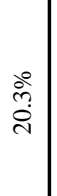 & $\begin{array}{l}\text { वें } \\
\text { तु }\end{array}$ & हे & 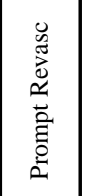 & 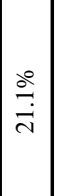 & $\begin{array}{l}\stackrel{\circ}{0} \\
\stackrel{+}{d}\end{array}$ & లి & 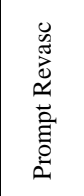 & $\begin{array}{l}\stackrel{0}{\circ} \\
\stackrel{\infty}{\infty} \\
\infty\end{array}$ & $\mid \begin{array}{l}\stackrel{0}{0} \\
\dot{\leftrightarrow}\end{array}$ & : \\
\hline & 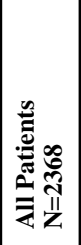 & 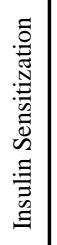 & 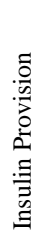 & 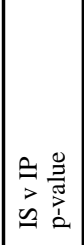 & 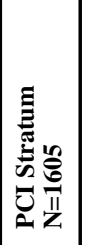 & 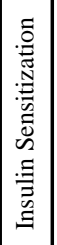 & 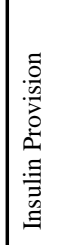 & 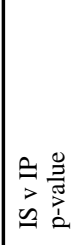 & 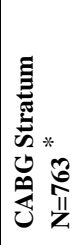 & 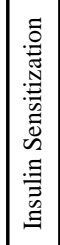 & 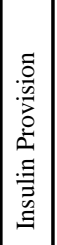 & 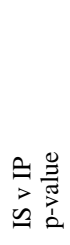 \\
\hline \multirow{4}{*}{ 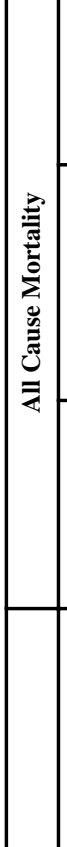 } & 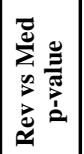 & $\begin{array}{l}\vec{\infty} \\
\dot{0}\end{array}$ & $\begin{array}{l}\infty \\
\infty \\
0 \\
0\end{array}$ & 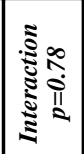 & 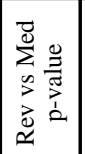 & $\begin{array}{l}0 \\
0 \\
0\end{array}$ & 足 & 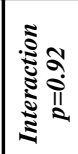 & 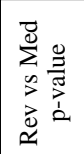 & 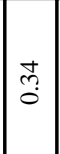 & $\begin{array}{l}0 \\
0 \\
0\end{array}$ & 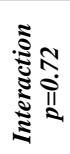 \\
\hline & 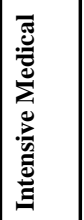 & 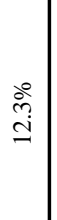 & $\begin{array}{l}\stackrel{0}{0} \\
\stackrel{0}{\mathrm{I}}\end{array}$ & \&. & 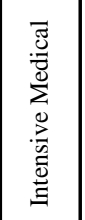 & $\frac{\circ}{\circ}$ & $\begin{array}{l}\stackrel{\circ}{0} \\
\stackrel{0}{9}\end{array}$ & do & 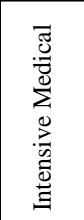 & $\begin{array}{l}\stackrel{\circ}{\ominus} \\
\stackrel{5}{\Xi}\end{array}$ & $\begin{array}{l}\stackrel{0}{0} \\
\dot{0} \\
2\end{array}$ & ㄹ. \\
\hline & 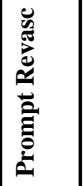 & 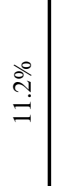 & $\begin{array}{l}\stackrel{0}{\tilde{U}} \\
\stackrel{\text { In }}{ }\end{array}$ & $\stackrel{n}{o}$ & 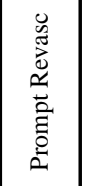 & $\begin{array}{l}\stackrel{0}{0} \\
\stackrel{一}{\subseteq}\end{array}$ & $\begin{array}{l}\stackrel{\stackrel{o}{+}}{=} \\
=\end{array}$ & $\hat{\imath}$ & 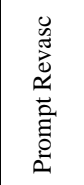 & 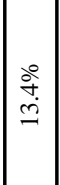 & $\mid \begin{array}{l}\stackrel{0}{2} \\
\stackrel{2}{2}\end{array}$ & $\begin{array}{l}\infty \\
\infty \\
0\end{array}$ \\
\hline & 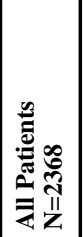 & 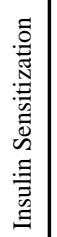 & 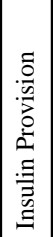 & 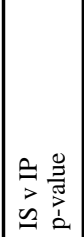 & 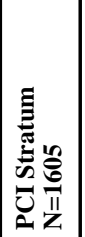 & 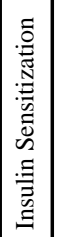 & 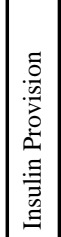 & 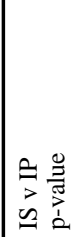 & 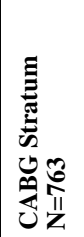 & 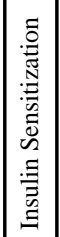 & 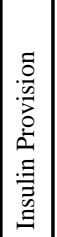 & 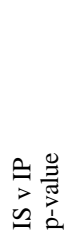 \\
\hline
\end{tabular}

苛 
